\title{
Viability of stressed Mycobacterium tuberculosis and association with multidrug resistance
}

\author{
Maria Conceição Martins ${ }^{1}$, Carmen Maria Saraiva Giampaglia ${ }^{1}$, Erica Chimara ${ }^{1}$, \\ Rosângela Siqueira Oliveira ${ }^{1}$, Danielle Vedovello ${ }^{1}$, Sidnei Miyoshi Sakamoto ${ }^{2}$, \\ Lucilaine Ferrazoli ${ }^{1}$ \\ ${ }^{1}$ Instituto Adolfo Lutz, São Paulo, SP, Brazil. \\ ${ }^{2}$ Universidade Federal Rural do Semi-Árido, Mossoró, RN, Brazil.
}

Submitted: March 25, 2011; Approved: September 10, 2012.

\begin{abstract}
This study investigated biological characteristics of recovered stressed $M$. tuberculosis isolates that failed to grow in differential culture media for phenotypic identification and in culture media containing anti-tuberculosis drugs for drug-susceptibility testing, despite of having grown in primary culture. It represents an improvement in the diagnosis of MDR tuberculosis and tuberculosis control.
\end{abstract}

Key words: Mycobacterium, multidrug resistance, culture growth, spoligotyping.

Tuberculosis has never been eradicated from the world and the emergence of multidrug resistant strains (MDR) of Mycobacterium tuberculosis has become a worldwide public health problem (Dalcolmo et al., 2007; World Health Organization 2000).

The expansion of MDR strains has been linked to specific genotypes classified by spoligotyping method (Dalla Costa et al., 2009; Gomes et al., 2011; Kamerbeek et al., 1997; Mendes et al., 2011; Von Groll et al., 2010). Isolation (primary culture), species identification (ID) and drug-susceptibility testing (DST) of M. tuberculosis are essential procedures for tuberculosis control (Collins et al., 1997). Delay in the diagnosis of MDR tuberculosis leads to patients with chronic disease and continued transmission in the community (Dalcolmo et al., 2007; World Health Organization 2000).

Some researchers showed that bacillary stress due to drug resistance or other stresses may reduce the capacity of in vitro growth of $M$. tuberculosis (Von Groll et al., 2010; Warner and Mizrahi, 2006). On the other hand, as cited by Von Groll et al. (2010), M. tuberculosis has the tendency to form clumps when grown in liquid media, this may lead to an unequal distribution of bacilli which may influence the recovery rates of subcultures. These phenomena can affect results of ID and DST and the absence of growth of drug- resistant isolates may delay the correct diagnosis of tuberculosis.

This study aimed to recover and investigate biological characteristics presented by frozen primary cultures of mycobacteria that have showed growth failure in the subcultures for ID and DST tests when they were submitted to a first analysis.

Primary cultures of mycobacteria analyzed at Instituto Adolfo Lutz (IAL), a reference laboratory for the state of São Paulo, Brazil, have been received from local as well as regional laboratories either in solid media as Ogawa or Löwenstein-Jensen or in liquid medium as $\mathrm{MB} / \mathrm{BacT}{ }^{\circledR}$ or BD BACTEC-MGIT 960 (Collins et al., 1997; Giampaglia et al., 2007; Susemihl et al., 1993).

At IAL, the quality of primary culture has been evaluated by macroscopic and microscopic observation before performing ID and DST tests (Monteiro et al., 2003). During the procedures ofID and DST, an inoculum of each culture with adequate growth was preserved at $-70^{\circ} \mathrm{C}$ in glass beads humidified with sauton medium containing $10 \%$ of glycerol (Giampaglia et al., 2009).

From January 2001 to February 2002, 40 primary cultures classified as adequate for analysis and presumptively identified as M. tuberculosis - by cord formation and culture morphology as cited by Monteiro et al. (2003) showed growth failure when subcultured in differential culture me-

Send correspondence to M.C. Martins. Instituto Adolfo Lutz, Seção de Bacteriologia Av. Dr. Arnaldo 351, $9^{\circ}$ andar, $01246-900$ São Paulo, SP, Brazil. E-mail: martinsesouza@uol.com.br. 
dia for phenotypic ID and in culture media containing antituberculosis drugs for DST by resistance ratio method (Collins et al., 1997).

One cryovial of each primary culture was removed from the freezer. Three glass beads were removed from the vial using a sterile loop and each one was inoculated into tubes of Löwenstein-Jensen, Ogawa and Middlebrook 7H9 (7H9) media, which were incubated at $37{ }^{\circ} \mathrm{C}$. If culture growth did not show within 60 days, the procedure were repeated once again to confirm its loss of viability.

The mycobacterial growth was analyzed by morphological characteristics and the average number of colonies in solid media was reported as (+) 20 to 100 colonies, $(++)$ more than 100 colonies (poor growth) and $(+++)$ more than 100 colonies (luxuriant growth). For a better standardization of each inoculum only subcultures from solid media were used in the additional tests.

The recovered primary cultures were submitted to phenotypic identification and to PCR-restriction fragment length polymorphism analysis (PRA) of the $h s p 65$ gene as previously described elsewhere (Collins et al., 1997; Devallois et al., 1997).

The resistance pattern of $M$. tuberculosis to isoniazid (I), rifampicin (R), ethambutol (E) and streptomycin (S) performed using by MGIT 960 (Giampaglia et al., 2007). Susceptibility to pyrazinamide $(\mathrm{P})$ was determined by pyrazinamidase activity (OPAS-OMS 1986). The spoligotypes obtained by the analysis of spacer oligonucleotide typing (spoligotyping) were compared to Bases de Donnèes: SPOLDB4 - Institute Pasteur de la Guadeloupe (2010). The strains for quality controls for the phenotypic and genotypic tests were M. tuberculosis H37Rv (ATCC 27294) and M. bovis-BCG (IAL 1850) from the culture collection of Instituto Adolfo Lutz.

The recovery rate of 40 primary cultures received on Ogawa $(n=14)$, Löwenstein-Jensen $(n=13)$ and liquid medium $(\mathrm{n}=13)$, which were preserved on glass beads, was $97.5 \%$. One isolate received on Löwenstein-Jensen (number 37) and failed to grow in all the inoculated media. The growth of isolates number $01,05,12,14,31,34$ was readily detected only at the second attempt to subculture and the recovery of 39 primary cultures was possible with media $7 \mathrm{H} 9$ and Ogawa or Löwenstein-Jensen. One primary culture received in Löwenstein-Jensen only grew in LöwensteinJensen and 7H9, two primary culture received in Ogawa only grew in Ogawa and 7H9, four primary cultures received in liquid medium only grew in $7 \mathrm{H} 9$ and Ogawa. The time for the subcultures to become positive ranged from 20 to 60 days in solid medium and from 15 to 40 days in liquid medium. Poor growth level (20 to 100 colonies) was detected in $14(36.0 \%)$ subcultures: five in solid medium and nine in liquid medium (Table 1).

Identification by phenotypic tests and by PRA $h s p 65$ method showed that all the recovered isolates belonged to the $M$. tuberculosis complex. Drug susceptibility testing of the 39 isolates showed that $13(33.3 \%)$ were susceptible to all the tested drugs, and $26(66.7 \%)$ were resistant to at least one of the five first-line antituberculosis drugs. Among the 26 resistant isolates, 18 (69.0\%) were MDR (Table 2).

Two isolates, susceptible to all the tested drugs $\left(\mathrm{n}^{0} 38\right.$, $n^{0} 39$ ) were unclassified by spoligotyping as they showed persistently no hybridization with the 43 spacer oligonucleotides. The remaining $37(94.8 \%)$ isolates showed 24 patterns, $18(72.0 \%)$ of them were unique pattern and six were clusters $(24.0 \%)$ consisting of two or three of the 19 remaining isolates (Table 2). Among the isolates included in clusters, $17(89.5 \%)$ were resistant to antituberculosis drugs and 13 (68.4\%) were MDR.

Matched patterns with SPOLDB4 showed that most of the isolates belonged to Latin-American-Mediterranean (LAM) family -12 isolates, followed by $\mathrm{S}$ - four isolates, Haarlem and modern tuberculosis strains (T) - three isolates each, LAM3/S convergent, Beijing and IS6110 low banding (X) - two isolates each, East-African IndianEAI1_SOM and Unknown (one isolate each). Seven orphan patterns matched with none at SPOLDB4 - Institute Pasteur de la Guadaloupe (2010). The reference strains were classified as spoligotyping pattern $451(\mathrm{H} 37 \mathrm{Rv})$ and 482 (M.bovis_BCG).

The present study showed the recovery of $97.5 \%$ of frozen primary cultures of mycobacteria that showed growth failure in the subcultures for ID and DST tests when they were submitted to a first analysis.

Table 1 - Average number of days required to recover primary culture of stressed M. tuberculosis strains - Instituto Adolfo Lutz 2001-2002.

\begin{tabular}{|c|c|c|c|c|c|c|}
\hline \multirow[t]{3}{*}{ Growth level } & \multirow{3}{*}{$\begin{array}{c}\text { Ogawa medium } \\
\text { Susceptible }\end{array}$} & \multicolumn{4}{|c|}{ Löwenstein-Jensen medium } & \multirow{3}{*}{$\begin{array}{c}\text { Middlebrook } 7 \mathrm{H9} \\
\text { medium } \\
\text { Resistant }\end{array}$} \\
\hline & & \multicolumn{4}{|c|}{ Number of strains/(\% days required for recovery) } & \\
\hline & & Resistant & Susceptible & Resistant & Susceptible & \\
\hline+ & $2(60.0)$ & $1(60.0)$ & $1(60.0)$ & $1(60.0)$ & $3(16.0)$ & $6(20.0)$ \\
\hline ++ & $5(30.0)$ & $13(34.6)$ & $4(32.5)$ & $13(34.6)$ & $6(17.5)$ & $11(18.0)$ \\
\hline+++ & $6(35.0)$ & $11(31.8)$ & $4(32.5)$ & $11(31.8)$ & $4(15.0)$ & $9(19.0)$ \\
\hline Total & $13(27.6)$ & $25(34.4)$ & $9(35.5)$ & $25(34.4)$ & $13(16.5)$ & $26(19)$ \\
\hline
\end{tabular}

Growth level- Solid medium (+) 20/100 colonies, (++) more than 100 colonies (poor growth) and (+++) more than 100 colonies (luxuriant growth); Liquid medium: $(+)$ few clumps, $(++)$ some clumps and $(+++)$ many clumps. 
Table 2 - Mycobacterium tuberculosis spoligotypes and drug susceptibility testing (DST) patterns - Instituto Adolfo Lutz, Brazil, 2001-2002.

\begin{tabular}{|c|c|c|c|}
\hline Type strain & Spoligotyping & Family & DST (isolate number) \\
\hline 1 & 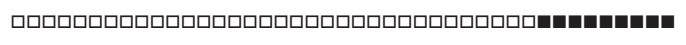 & Beijing & IES (31), susceptible (32) \\
\hline 4 & | & LAM3/S convergent & RP (29), IRES (30) \\
\hline 17 & 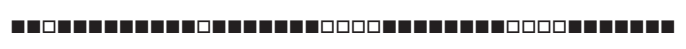 & LAM2 & susceptible (4) \\
\hline 20 & 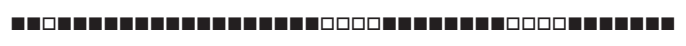 & LAM1 & $\operatorname{IR}(23)$ \\
\hline 33 & " & LAM3 & susceptible (1) \\
\hline 34 & 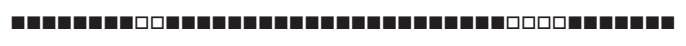 & S & IRPES (21/22), IRP (23), IR (33) \\
\hline 42 & 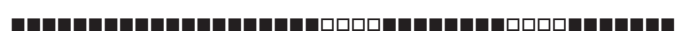 & LAM9 & IRPE (6), IRP (5 12), RE (7), IR (13), susceptible (10) \\
\hline 48 & 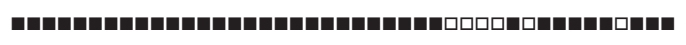 & EAI1_SOM & susceptible (40) \\
\hline 50 & 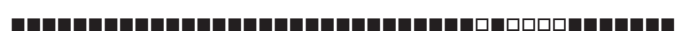 & $\mathrm{H} 3$ & IRP (19 34), P (35) \\
\hline 60 & " & LAM4 & IRPES (8) \\
\hline 64 & " & LAM6 & IRPES (9) \\
\hline 119 & " & $\mathrm{X} 1$ & $\mathrm{I}(20)$ \\
\hline 137 & 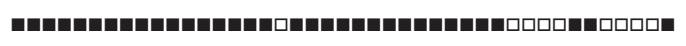 & $\mathrm{X} 2$ & susceptible (18) \\
\hline 157 & 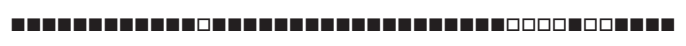 & $\mathrm{T} 3$ & susceptible (17) \\
\hline 534 & 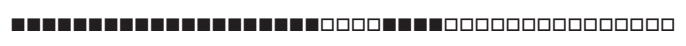 & Unknown & susceptible (14) \\
\hline 573 & 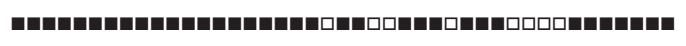 & $\mathrm{T} 1$ & susceptible (16) \\
\hline 1905 & 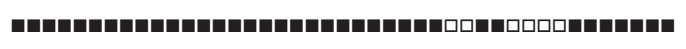 & $\mathrm{T} 1$ & $\operatorname{IRPE}(36)$ \\
\hline 0 & ' & Orphan & susceptible (11) \\
\hline 0 & 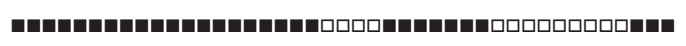 & Orphan & susceptible (15) \\
\hline 0 & " & Orphan & $\operatorname{IRP}(24)$ \\
\hline 0 & " & Orphan & $\mathrm{S}(25)$ \\
\hline 0 & " & Orphan & IS (26) \\
\hline 0 & " & Orphan & I (27) \\
\hline 0 & 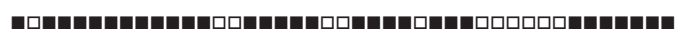 & Orphan & $\operatorname{IRP}(28)$ \\
\hline
\end{tabular}

Spoligotyping pattern: black square = hybridizing; empty square = nonhybridizing; Type strain and Family as described by Bases de Données:SPOLDB4 [cited Oct., 2010]. Available from: http://www.pasteurguadeloupe.fr/; DST pattern: $\mathrm{I}=$ isoniazid, $\mathrm{R}=$ rifampicin, $\mathrm{E}=$ ethambutol, $\mathrm{S}=$ streptomycin, $\mathrm{P}=$ pyrazinamide.

Our already published study about maintenance of M. tuberculosis on glass beads (Giampaglia et al., 2009) showed that almost $100.0 \%$ of the 730 investigated cultures remained viable after 1 to $5 \mathrm{yr}$ of frozen. The fact that in this study six cultures only grew at the second attempt may be due to the tendency of mycobacteria to form clumps in liquid media (Von Groll et al., 2010). Unequal distribution of bacilli may have occurred in glass beads and may have influenced the recovery rate of mycobacteria.

Others factors that may have influenced the recovery rate of mycobacteria were chromosomal mutations in $M$. tuberculosis that are responsible for resistance to most of the anti-tuberculosis drugs, including rifampin and isoniazid. These mutations have been associated with a fitness cost, seen as a decreased growth rate in vitro (Dalla Costa et al., 2009; Warner and Mizrahi, 2006). Although chromosomal mutations were not investigated in this study our results are consistent with this premise as $66.7 \%$ of the stressed M. tuberculosis isolates were resistant to at least one of the five first-line antituberculosis drugs and $69.0 \%$ of them were MDR.

The average days to recover susceptible strains was 27.6 (range 20-60 days) in Ogawa and 16.5 (range 1520 days) in $7 \mathrm{H} 9$ medium and to recover resistant strains was 34.4 (range 20-60 days) in Ogawa and 19 (range 1530 days) in 7H9 medium. This result is in agreement with the study of Von Groll at al. (2010) that showed that MDR isolate presented a lower reproductive efficiency. No difference was observed between the average days required to recover susceptible and resistant strains of $M$. tuberculosis in Löwenstein-Jensen.

Spoligotyping allowed the classification of 24 spoligotyping patterns including those representing the major families of tubercle bacilli: Beijing, Haarlem, LAM and EAI. Among the spoligotyping clusters, we found a high proportion of drug-resistant isolates already described in Brazil (Dalla Costa et al., 2009; Gomes et al., 2011; Mendes et al., 2011). This study detected some clusters of drug-resistant and drug-susceptible mycobacteria as those 
observed by Mendes et al. (2011) in São Paulo city, showing that these strains have been circulating in the São Paulo state.

Our findings emphasize the importance of recovered stressed M. tuberculosis isolates that failed to grow in differential culture media for phenotypic ID and in culture media containing antituberculosis drugs for DST, despite of having grown in primary culture. It represents an improvement in the diagnosis of MDR tuberculosis and tuberculosis control.

\section{Acknowledgments}

We are grateful to Christophe Sola $\mathrm{PhD}$ for performing the spoligotype database analyses and to Ive Brunelli MA for carefully proofreading the text.

\section{References}

Collins CH, Grange JM, Yates MD (1997) Tuberculosis Bacteriology Organization and Pratice. $2^{\text {nd }}$ ed. Butterworth-Heinemann, Oxford.

Dalcolmo MP, Andrade MKN, Picon PD (2007) Tuberculose multirresistente no Brasil: histórico e medidas de controle. Rev Saúde Pública 41, Suppl 1:34-42.

Dalla Costa ER, Ribeiro MO, Silva MSN, Arnold LS, Rostirolla DC, Cafrune PI, Espinoza RC, Palaci M, Telles MA, Ritacco V, Suffys PN, Lopes MC, Campelo CL, Miranda SS, Kremer K, da Silva PE, Fonseca LS, Ho JL, Kritsky AL, Rossetti ML (2009) Correlations of mutations in Kat G, oxyRahpC and InhA genes and in vitro susceptibility in Mycobacterium tuberculosis clinical strains segregated by spoligotype families from tuberculosis prevalent countries in South America. BMC Microbiol 9:39.

Devallois A, Goh KS, Rastogi N (1997) Rapid identification of Mycobacteria to species level by PCR-Restriction Fragment Length Polymorphism Analysis of the hsp 65 gene and proposition of an algorithm to differentiate 34 mycobacterial species. J Clin Microbiol 35:2969-2973.

Giampaglia CMS, Martins MC, Vieira GBO, Vinhas SA, Telles MAS, Palaci M, Marsico AG, Hadad DJ, Mello FCQ, Fonseca LS, Kritski A (2007) Multicentre evaluation of an automated BACTEC 960 system for susceptibility testing of $M y$ cobacterium tuberculosis. Int $\mathrm{J}$ Tuberc Lung Dis 11:986-991.
Giampaglia CMS, de Brito AC, Martins MC, Ueki SYM, Latrilha FO, de Oliveira RS, Yamauchi JU, Telles MAS (2009) Maintenance of Mycobacterium tuberculosis on Glass Beads. Ann Clin Lab Sci 39:51-54.

Gomes HM, Elias AR, Oelemann MA, Pereira MA, Montes FF, Marsico AG, Kritski AL, Filho LD, Caldas PC, Possuelo LG, Cafrune P, Rossetti ML, Lucena N, Saad MH, Cavalcanti HR, Leite CQ, Brito RC, Lopes ML, Lima K, Souza M, Trindade RD, Zozio T, Sola C, Rastogi N, Suffys PN (2011) Spoligotypes of Mycobacterium tuberculosis complex isolates from patients residents of 11 states of Brazil. Infect Genet Evol Sep 1. [Epub ahead of print]

Kamerbeek J, Schouls L, Kolk A, van Agterveld M, van Soolingen D, Kuijper S, Bunschoten A, Molhuizen H, Shaw R, Goyal M, van Embden J (1997) Simultaneous detection and strain differentiation of Mycobacterium tuberculosis for diagnosis and epidemiology. J Clin Microbiol 35:907-914.

Mendes NH, Melo FA, Santos AC, Pandolfi JR, Almeida EA, Cardoso RF, Berghs H, David S, Johansen FK, Espanha LG, Leite S, Leite CQ (2011) Characterization of the genetic diversity of Mycobacterium tuberculosis in São Paulo city, Brazil. BMC Res Notes Jul 29, 4:269.

Monteiro PHT, Martins MC, Ueki SYM, Giampaglia CMS, Telles MAS (2003) Cord formation and colony morphology for the presumptive identification of Mycobacterium tuberculosis complex. Braz J Microbiol 34:171-174.

OPAS-OMS (1986) Manual de Normas y Procedimientos Tecnicos para la Bacteriologia de la Tuberculosis. Parte III Sensibilidad del Mycobacterium tuberculosis a las Drogas. La Identificatión de Micobactérias. Nota Técnica 28. Martinez.

Institute Pasteur de la Guadeloupe. Tuberculose et Mycobactéries. Bases de Données - SPOLDB4. Available at: http://www.pasteurguadeloupe.fr/ accessed October 2010.

Susemihl MAAMM, Ferrazoli L, Ueki SYM, Gimenez RD, Palaci M (1993)The use of Ogawa-Kudoh method for culturing mycobacteria. Bras Pat Clin 29:51-54.

Von Groll A, Martin A, Portaels F, Silva PEA. Palomino JC (2010) Growth kinetics of Mycobacterium tuberculosis measured by quantitative resazurin reduction assay: a tool for fitness studies. Braz J Microbiol 41:300-303.

Warner DF, Mizrahi V (2006) Tuberculosis chemotherapy: the influence of bacillary stress and damage response pathways on drug efficacy. Clin Microbiol Rev 19:558-570.

World Health Organization. (2000) Antituberculosis Drug Resistance in the World - Prevalence and Trends. Report 2. Publication WHO/CDS/TB/2000.278, Geneva.

All the content of the journal, except where otherwise noted, is licensed under a Creative Commons License CC BY-NC. 